\title{
Oblique Impact on Crashworthiness: Review
}

\author{
Tan Sze Pei, Siti Nadiah bt. Mohd Saffe, Siti Aishah bt Rusdan \& Nurul Nadiah bt \\ Nor Hamran
}

\author{
Faculty of Engineering technology, University Malaysia Pahang, kuantan 26300, Malaysia
}

\begin{abstract}
This paper reviewed the crashworthiness of foam-filled thin-walled structure subjected to oblique loading conditions. Crashworthiness is the most important part in designing a safety vehicle, so, the types of collisions, crashworthiness parameter and the modes of collapse of structural components are included in this part. Secondly, the energy absorber regarding the axial loading and oblique loading in terms of geometry parameters and materials of the previous research is reviewed. In addition, the manufacturing and properties of aluminium foams with the collapse behavior of foam-filled structures are studied to understand the performance and the relation under loading.
\end{abstract}

Indexed Terms: Crashworthiness, Oblique, Energy Absorber.

\section{INTRODUCTION}

Crashworthiness is an important part of designing a vehicle. During a crash, a vehicle is designed to absorb the energy from the impact of a collision. It acts as a protection to the occupants in the vehicle from the collision during a crash. The crumple zones of vehicle absorb the energy from the impact and deflect it away from the occupants. In the other hand, the design of the modern vehicle is important to reduce the weight of the structures, in order to increase fuel efficiency. According to a news reported by The New York Times stated that, drivers worried about running into older, heavier vehicles on the road might be reassured that composite material is exceptionally stiff and strong, lighter weight for fuel economic, and will have to pass muster, including crash tests, with the National Highway Traffic Safety Administration [1]. To meet these requirements, the advanced and lightweight engineering materials are the first choice in the technology of crashworthiness.

In view of dissipating kinetic energy during impact, much research work into crashworthiness has been done since 1960s especially in the automotive and military industries [2]. Although passenger safety has improved significantly since 1966, when federal motor vehicle standards were first legislated, new challenges exist with consumer and legislative pressure to develop "green", low-emission, fuel-efficient cars. The most direct method of reducing fuel consumption and emissions is to reduce the weight of the vehicle. New vehicle structures will incorporate space frame technology. Space frames are composed of thin-walled components that are formed to meet at nodes. In a crash, the thin-walled components of the space frame absorb energy through a combination of bending and axial collapse [3]. The design of the structure and its crash response due to collision are involving a highly complex and nonlinear analysis. In the other hand, the frontal collisions are considered here because in compare to other modes of collision such as side-impact, rear and roll-over, the frontal collision impact has a higher fatality rate [4]. The sufficient energy absorbed by the crashworthy structure is able to minimize the serious injuries or prevent permanent brain damage to the occupants [5-6]. Thus, the design of the structures for controlling a collapse could consider a factor of lighter weight which more efficient than the often heavier structure on design of catastrophic failure, such as metals [6]. 
In this study, instability will cause the energy absorption capacity to differ significantly from the expected values. One of these cases, namely the effect of obliquity, is discussed.

\section{TYPES OF COLLISION DURING CAR CRASH}

Typically, there are two modes of car accidents: (i) impact from any direction (front, rear, left, and right side) and (ii) rollover. All crashworthiness features are designed for these typical accident modes. For example, crumple zones and airbags for frontal and rear impact and side impact zones for side impact. The probability of different collision types are shown in Figure 1 as published by Mercedes-Benz in 1994 [7]. The reports for earlier models of Mercedes-Benz [8] and the U.S. Department of Transportation 2014 annual report [9] show a very similar accident probability distribution.

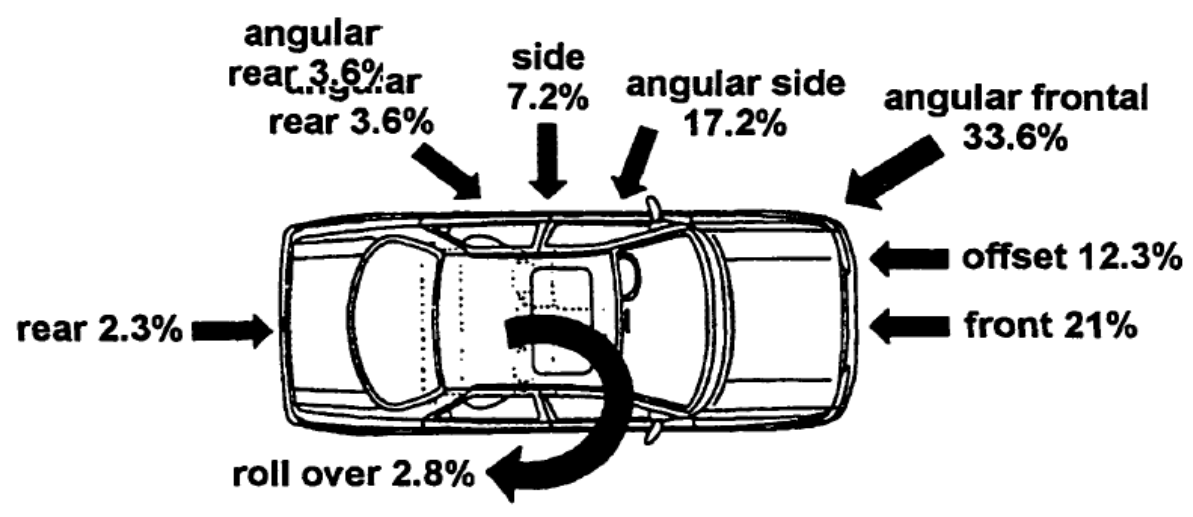

Figure 1: Statistical analysis of crash direction [ Wallentowitz \& Adam (1996)

The number of fatalities in vehicle crashes is at its peak level since 1990 [9]. A major contributor to this fact is the increase in the number of light trucks and vans (LTVs) and sport utility vehicles (SUVs) on the roads. For example, the number of fatalities in car-LTV collisions is 1.5 times higher than that in car-car collisions [10]. This is because the LTVs are found to be three times more aggressive than passenger cars, where aggressivity refers to the ability/inability of a vehicle to protect occupants within the collision partner vehicle. The fatality rate in 2002 (number of fatalities per 100M vehicle miles travelled) was, however, unchanged compared to 2001, and it has seen a steady decrease since 1995.

\subsection{Frontal Impact}

The available reports indicate that frontal collision is the predominant type of collision for all vehicle types in either single or multiple vehicle collisions, accounting for approximately $50 \%$ of all accidents. Due to the high impact speed and, consequently, high impact forces and energy, frontal collision is also considered the most severe. However, this type of collision only accounts for slightly more than $30 \%$ of all severe and fatal injuries. In a majority of situations, frontal impact will not be a head-on full-width impact (Figure 1). Rather, a certain offset or oblique incidence will exist. In a full-width impact, energy absorption of the structure is maximized, and the integrity of the occupant compartment is maintained, except for in the case of very high-speed crashes. In an offset impact, a smaller area of the structure, on one side of a vehicle's front end, will experience all the crash energy. This difference between these two types of impact needs to be taken into account when conducting tests for improved 
crashworthiness. This is because the full-width impact test results in high occupant compartment decelerations and it is very demanding on the restraining systems (airbag, seat belts, etc.), while the offset test is very demanding on the structure for the higher energy absorption and prevention of intrusion into occupant compartment. By introducing the offset test in the early 1980s, for instance, and taking into account the crashworthiness of the vehicle under offset impacts in designing their vehicles, Mercedes Benz was capable of reducing the percentage of fatalities in frontal collisions [8]. Several different frontal test conditions and crash modes are shown in Figure 2. Four basic test configurations are used to represent different frontal collision situations where the impact is distributed or localized, oblique or head-on, offset or centered. These configurations can represent a collision with the fixed object, another vehicle, or both other important styles.

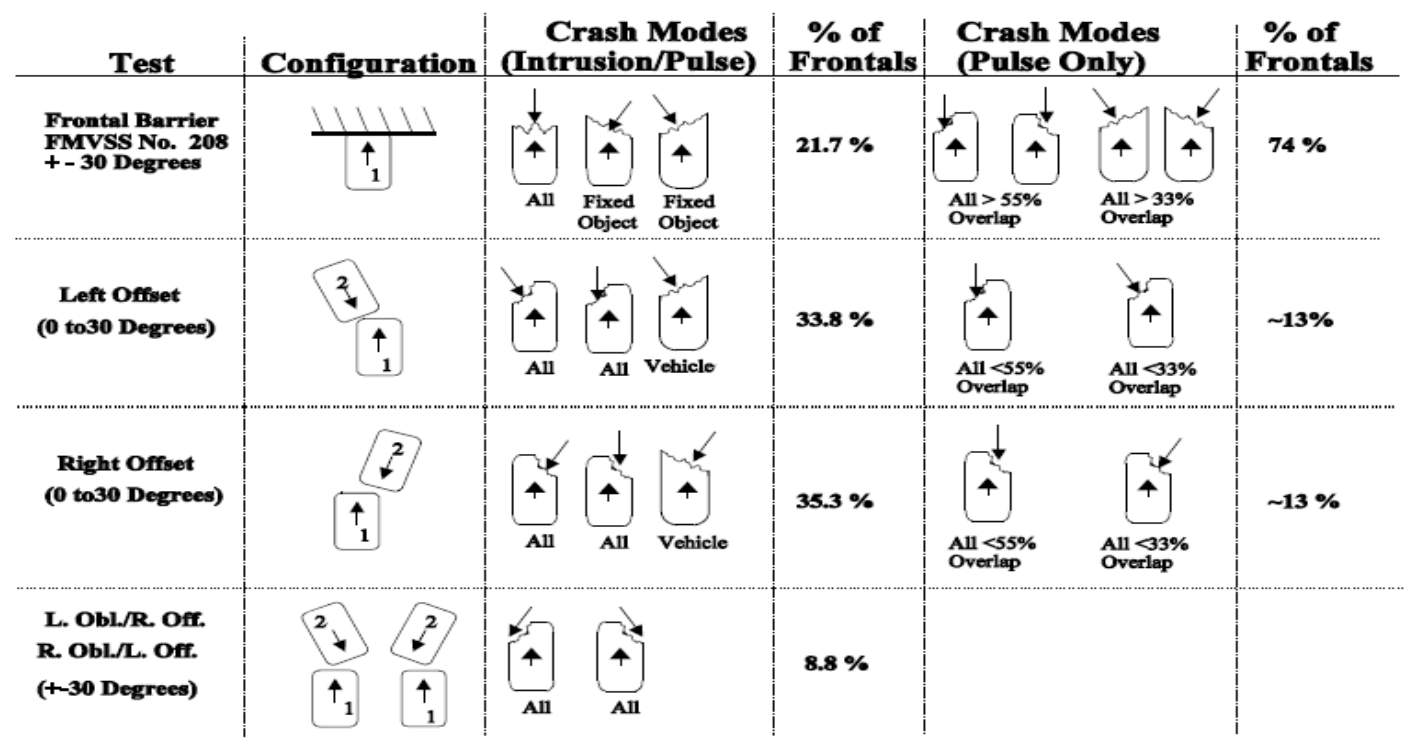

Figure 2: Possible frontal test conditions [11].

\subsection{Side Impact}

Side collisions between 1980 and 2001 yielded a $24 \%$ decrease in fatality rate per million cars registered. Although considerable, this number is still much lower than the decrease of 52\% in the case of frontal collisions for the same period. Reports also indicate that in recent car models, more than $50 \%$ of deaths are assigned to side collisions, which is $20 \%$ more than in 1980. The primary reason for this great fatality of side collisions is the increasing size-mismatch between the LTVs and passenger cars, causing nearly $60 \%$ of deaths in side collision to be the result of LTV-car collisions. In order to simulate this most severe case of impact by LTV, the standard side impact test is conducted perpendicular to the driver's side of the vehicle using a barrier that accounts for the vehicle height and the specific shape of LTVs' front ends. However, side impact collisions remain very complex and require research input in order to improve crashworthiness and aggressivity of vehicles in side collisions [10].

\subsection{Rear Impact}

Rear impact collisions account for only 1-3\% of vehicle accident fatalities. This is because this type of crash has the lowest probability of happening and because the speeds at which the collision occurs are low. Typical test configurations for this case are either rear-bumper-to-pole test at $5 \mathrm{mph}$ or front-to-rear two-vehicle collision with both vehicles moving at similar speeds. The factor that affects the crashworthiness in rear collisions is the variability in possible 
configurations due to the considerable change in height of car's rear end caused by braking, number of passengers, and baggage, among others.

\subsection{Rollover}

The number of passenger-vehicle occupant fatalities in rollovers has increased by $5 \%$ from 2001 to 2002. Although the number of fatalities in passenger cars has been declining since 1980, the great increase in the number of SLTV rollover fatalities causes the above increase as well as contributes to nearly half of the increase in all occupant fatalities. The reason for SUVs being prone to rollover lies in their relatively high center of gravity as compared to their width. Once rolled over, the roof of an SUV crashes inward due to insufficient support. This usually causes injuries to the head and neck regions of the occupants.

\section{PRINCIPLES OF CRASHWORTHINESS DESIGN}

The axial loading is the most efficient mode of deformation and it is also the most difficult to attain. A structure that starts to deform axially can suddenly buckle in the global bending mode, causing a significant drop in the capacity of the structure to absorb the impact energy. This behaviour may completely alter the crash performance of the structures, hence it is important to understand the mechanics of this transition so that proper measures can be taken to avoid it. Therefore, the objectives of good structural crashworthiness design are [2]:

\subsection{Irreversible Energy Conversion}

During collision, an impact energy hits to the vehicle by crush force. An important fundamental of design of the structure and the materials used should be able to absorb as much of the impact energy which is free from elastic strain energy. If the vehicle is designed as elastic strain energy, the structure will returns to original shape after undergoing a maximum compression due to release of the elastic energy. This caused the vehicle rebounded like a spring. Hence, it is completely desirable to have inelastic energy absorption during collision to avoid the "spring back "effect.

\subsection{Constant and Stable Crush Force}

To minimize the changes in deceleration during collision, the crush force on the vehicle due to impact should remain almost constant and kept below a threshold value. Rapid changes in deceleration can cause brain injuries as indicated by the HIC. The energy absorbing device ideally should possess a rectangular force displacement characteristic.

\subsection{Long Stroke}

Dissipating of kinetic energy during a crush is very important. Most of the kinetic energy is dissipated in terms of work done by the impact force to crush the structure to a particular distance. Most of this work, which is the crush force times the magnitude of the displacement of the structure, is converted into inelastic strain energy of the structure. So, when an energy absorbing device is designed to have a long stroke (i.e. larger useful crush distance) and high energy absorption, it able to minimize the injury of the occupant in the vehicle by reducing the intrusion of the structure into the occupant's compartment. Hence, this may retain a survival space for the occupants. 


\subsection{Light Weight with High Specific Energy Absorption Capacity}

As we known, the crashworthiness is an important issue in a design of a vehicle. The additional features may be designed and added to the existing structure. These may increase the weight of the vehicle which in returns increases the fuel consumption. Hence to reduce or minimize the impact on the overall weight of the vehicle, energy absorbing devices should be light in weight yet possessing high specific energy absorption capabilities.

\section{ENERGY ABSORBER}

\subsection{Axial Loading}

A lot of works have been done in understanding the energy absorption capabilities of energy absorber under axial loading scenario. Analytical, numerical and experimental studies on axial structural collapse have mainly focused on the mode of collapse, the peak force, the mean force, and the energy-absorption characteristics. Most of the studies are focusing on geometry and material used in designing energy absorber.

Thin-walled tube with simple geometry profiles has received the most attention in axial crushing studies. Langseth \& Hopperstad [12] studied the static and dynamic behaviour of square thin-walled tubes subjected to axial loading by varying the temper, wall thickness and impact velocity. The wall thickness was $1.8,2.0$ and $2.5 \mathrm{~mm}$, while the impact velocity was in the range of 8 to $20 \mathrm{~m} / \mathrm{s}$. The behaviour between static and dynamic tests was also compared. The results showed that the mean load ratio between dynamic and static test is a decaying function with respect to the axial displacement which indicates a strong inertia effect to the straight square tube. in an another study, Jensen et al. [13] once again carried out static and dynamic tests to study the effect of geometry and impact velocity on the behaviour of axially loaded square thin-walled extrusions. From this study, inertia effect was observed by varying the length of the tube. The results showed that more energy is absorbed in the progressive buckling mode than in the global bending mode. Meanwhile, Zhang et al. [14] introduced patterns to the surface of thin-walled square tubes to improve energy absorption capacity under axial compressive loads. Two types of patterns was constructed where by pattern A was aimed at triggering the extensional mode while pattern $\mathrm{B}$ was intended to develop new collapse mode. Numerical results showed that pattern A absorbed 15-32.5\% while pattern B absorbed 54-93\% energy compared with the conventional tubes.

Besides square thin-walled tubes, cylindrical tubes have also attracted researcher's attention due to their high stiffness and strength, low weight, and ease of manufacturing process which contribute to a low cost of energy absorber devices [15]. Most of the past literatures of thinwalled circular tubes were studying the tube's collapse behaviour and derivation of empirical model. Alexander [16] was the first person who computes the mean collapse load for cylindrical tubes and the tubes deforming in concertina mode. Also, Empirical expression was derived by other researchers [17-18] to propose an improved model which there was a formula surprisingly applicable to both axisymmetric and non-axisymmetric modes [19]. Al Galib \& Limam [20] performed an experimental and numerical study of the crash behaviour of circular tubes and compared it with the available analytical solutions. It showed a good agreement between them and some effect of geometrical imperfection were made. Among many literatures on circular tube, work of [21] was found to study the geometrical side. They designed two new structures of circular tubes which the first design was a rigid steel ring is press-fitted on top of circular aluminum tubes, while the second design was some wide grooves that are cut from the outer surface of steel circular tubes. The finding proved that the suggested structural designs can improve energy absorption characteristics of circular tubes significantly under axial loading. 
Recently, tapered or frusta tubes have been considered desirable impact energy absorber due to desirable constant mean crush load-deflection response under axial loading [22]. However, relatively few studies have been reported on the energy absorption performance of such tubes compared with straight tubes. Singace et al. [23] investigated the influence of end constraints of circular frusta and found out that frusta are more stable as a structure as compared to cylinders. However, this study was meant for ship protection. Ahmad \& Thambiratnam [24] investigated the effect of foam filling on the dynamic response and energy absorption characteristics of thin- walled conical tubes using finite element simulations. Results indicate that the foam filler stabilizes the crushing process. Besides those tubes, rectangular or square tapered tubes also have been given focus recently. Nagel \& Thambiratnam [25] compared the energy absorption response of straight and tapered thin-walled rectangular tubes by varying wall thickness, taper angle, impact mass and impact velocity. The results indicate that the energy absorption response of tapered tubes can be controlled via its wall thickness and taper angle. Mirfendereski et al. [26] investigated the axial crushing of foam-filled tapered thin-walled rectangular tube and find that foam density has no significant effect on the initial peak load but has increase the mean load, the absorbed energy and the crush force efficiency as the foam density increases.

There are many more researches that are still active studying on axial crushing of energy absorber includes the geometry behaviour of multi-cell column [27-29], multi-tubes [30], multicomer thin-walled columns [31], effect of trigger mechanisms on tubes [32], and usage of various foam fillers inside tubes [33-35]. Besides, selection of materials is also important in the study of axial crushing of energy absorber. Steel has been extensively used in energy-absorbing structures [21, 2936$]$ due to low prices combined with excellent ductility. But the need to reduce structural components mass has increased in the recent years. Hence, the use of aluminum tubes has been frequently promoted [28, 34]. However, research of both materials is still going on until now. In the other hand, Structural optimization is also being interest nowadays to seek for the optimal design. Latest optimal design works are found to seek for multi- comer columns [31], foam-filled beam [36-27], conical frusta [38], partially tapered rectangular tubes [39], and multi-cell sections [40].

\subsubsection{Oblique Loading}

Not much effort was been found in designing energy absorber for oblique loading. Han and Park, [41] studied the crushing behavior of thin-walled square columns subjected to oblique loads and found out that there is critical load angle at which transition takes place from the axial collapse mode to the bending collapse mode. Extensive study on square columns was done [42] by substituting aluminium alloy to the columns and varying load angle, tube thickness, length, heat treatment and impact velocity. Results showed that collapse mode seems to depend on both load angle and thickness. Another study by Reyes et al. [43] on square aluminium tubes was done using computer simulation of LS-DYNA. Reyes et al. [44] further the study by introducing aluminium foam-filled into the square column. They performed experimental study by varying load angle, heat treatment, and foam density on numerical study by using LS-DYNA. The study shows that high density aluminium foam filler increase the energy absorption but the specific energy absorption is lower compared to the empty columns. Instead of study tapered tubes under axial loading. Nagel \& Thambiratnam [45] also study tapered tubes response under oblique loading. They compared the energy absorption response of straight and tapered thinwalled rectangular tube by varying load angle, impact velocity, and tube dimensions. It found that the mean load and energy absorption decrease significantly as the load angle increases. Study of foam-filled structure under this condition was done by Ismail [46] and found out that energy absorption capability decreased as the load angle increased. There is good interaction between wall and foam by which observed for higher foam density resulted in higher energy absorption. Ahmad et al. [24] investigated dynamic energy absorption characteristics of foamfilled conical tubes which also done under axial crushing. For oblique loading, they study the 
tube response by varying load angle and geometry parameters. Qi et al. [47] investigated the crash behaviour on several geometric parameters of single-cell and multi-cell tubes by numerical method. Their work shows that the multi-cell tapered tube performed the best crashworthiness performance under oblique loading. Song [48] also studied the square tubes calibrated with windows subjected to oblique impact loading by the numerical method. Song utilized the variables for the sake of the load angle, the geometrical parameters of window, and the impact velocity. It found that the energy absorption is much lower than the conventional tube. Fang et al. [49] investigated rectangular multi-cell tubes and introduced a formula to evaluate the mean crushing force under oblique loading. Conical structures under inclined impact were investigated by Zhang et al. [50] and optimal solution was identified using optimization algorithms. Yang \& Qi [51] and Djamaluddin et al. [52] studied on conventional tube filling with filler, both result showed the filled tube works better than the empty tube. In addition, a multi-objective optimization design (MOD) method was employed for the crashworthiness design of multi-cell thin-walled tubes [39, 53-54]. The study shows that conical tube has ability to withstand oblique impact as effectively as axial impact and energy absorption capability of filled tube is better compared to empty tube.

\section{CRASHWORTHINESS PARAMETERS}

Several performance indicators have been developed to evaluate the effectiveness of a given energy absorbing device component for crashworthiness applications. An ideal energy absorber would capable of attaining maximum load immediately and maintaining it for the entire length of the component. The goal to design an efficient energy absorbing device is to maximum its stroke, to have its mean load equivalent to the peak load, and to have a high specific energy absorption capability. These parameters are defined as below [55].

\subsection{Peak Load}

Peak load the highest load required to cause significant permanent deformation and distortion onto a component. It is important in crashworthiness parameter for two reasons. Firstly, during a low-speed and low-energy impacts, it is desirable that no permanent deformation takes place, as this would be considered damage to a structure. Secondly, peak load is often the maximum load observed in the useful stroke of the energy absorbing device because it has a direct influence on the loading of occupants in a vehicle.

\subsection{Specific Energy Absorption (SEA)}

SEA indicates the total energy absorbed in a crush, $\mathrm{U}$, in crushing the structure is equal to the area under the load-displacement curve. Where,

$$
\mathrm{U}=\int_{0}^{\mathrm{d} \max } \mathrm{FdS}
$$

Hence, the specific energy absorption is defined as the energy absorbed per unit mass of material as given in equation 2

$$
E_{S}=\frac{U}{m} \text {, where } m \text { is the crushed mass of the component }
$$

\subsection{Stroke Efficiency (SE)}

During a load displacement response of a crash component, the load will start to rise steeply due to densification at the particular maximum crush displacement. Thus, this maximum displacement is the useful displacement of the component. Meanwhile, geometry efficiency of 
an energy absorbing device is therefore defined as the ratio of the maximum displacement to the total length of the component. This is known as stroke efficiency.

\subsection{Average Crush Load}

Average crush load also known as mean load. The mean crush load $\left(\mathrm{P}_{\mathrm{m}}\right)$ is defined as the energy absorbed divided by the crushing distance $(\Delta \mathrm{L})[56]$

$$
P \mathrm{~m}=\frac{\mathrm{E}}{\Delta L}
$$

It is a ratio of the energy absorbed in the crush zone (Figure 2) to the crush distance in the crush zone.

\subsection{Crush Force Efficiency (CFE)}

The average and peak load are important parameters to be determined as they are directly related to the deceleration that will be experienced by the occupants in a vehicle. The best way to quantify this is to define a ratio between the mean load to the peak load. And this ratio is crush force efficiency. If the ratio is close to unity, the absorber is crushing at a value close to the peak load, hence minimizing the changes in deceleration as desired. On the other hand, if this ratio is away from unity, indicates that there are rapid changes in the deceleration and this is dangerous to have in designing a vehicle.

\section{FAILURE MODE}

For the primary concern in failure mode study are the axial mode of collapse and bending mode of collapse of structural components. Other modes of failure such as tube inversion or tube splitting and curling are not discussed here. Also, in this discussion, we refer specifically to metallic structural components. Different responses can be expected if fiber-reinforced composites are used, in which case the crush process is often accompanied by fracture and interlaminar shearing, rather than by plastic deformation [57-58].

\subsection{Axial Collapse of Columns}

The "pioneering" study in plastic folding of tubular structures was carried out by Alexander [16]. In his study, an approximate theory for the collapse of thin cylindrical shells under axial loading was derived. Alexander assumed that the shell collapses in the form of a "concertina" with straight-sided convolutions. The work that is required to deform a metal in one such convolution is used to cause bending at circular joints and stretch the metal between the joints. If this work is equated to the work done by the mean collapse load, a solution of the type:

$$
\mathrm{F}_{\text {mean }}=\mathrm{Ch}^{1.5} \sqrt{\mathrm{D}_{\text {shell }}}
$$

is obtained, where $\mathrm{h}$ is the thickness of the cylindrical shell, $\mathrm{C}$ is the material-dependent constant, and Dshell is the diameter of the shell. The main kinematic assumption made in this model is that one fold is formed at a time. Wierzbicki et al. proposed several improvements to this solution [59-60]. In [59], the stationary plastic hinges were replaced by moving hinges resulting in a more realistic deformed shape with improved prediction of the mean crush load. In [60], the assumption was made that two folding waves are being created in an active crush zone. Two cases were compared in that case. In the first, a model with two straight elements constrained by stationary hinges was analyzed and the final solution compared favourably with that in equation (6). In the second case, a more realistic deformed shape and a more accurate prediction for mean load were obtained by using two "S" shapes superfolding-elements. The 
solution was in the form given by the above equation, except for the constant $\mathrm{C}$ which was approximately $40 \%$ higher than in the Alexander's solution. This model was also capable of predicting the existence of intermediate peaks in the load-displacement response.

The superfolding-element was initially developed by Wierzbicki and Abramowicz [61] as a two-degree of freedom comer element. They used this element to represent the deformed section of a prismatic column undergoing quasi-static compression loading. Their resulting theoretical analysis represents the basis for studying the progressive crushing of square and rectangular columns. Abramowicz and Jones [17] have further extended this work to include the dynamic crushing strength of columns, as well as the experimental validation of the proposed theory. Two basic types of superfolding-elements for square columns are shown in Figure 3. The energy absorbed in these basic element types is [61-62] :

$$
\begin{aligned}
& \mathrm{E}_{1}=\mathrm{M}_{0}\left(8.880 \mathrm{Hb} / \mathrm{h}+2 \pi \mathrm{c}+4.592 \mathrm{H}^{\wedge} 2 / \mathrm{b}\right) \\
& \mathrm{E}_{2}=\mathrm{M}_{0}\left(\left(2 \pi \mathrm{H}^{\wedge} 2\right) / \mathrm{h}+2 \pi \mathrm{c}+\pi \mathrm{H}\right)
\end{aligned}
$$

where $\mathrm{M}_{0}=\sigma_{0} \mathrm{~h}^{2} / 4, \sigma_{0}$ is column wall flow stress, $\mathrm{h}$ is wall thickness, $\mathrm{E}_{1}$ is defined in Figure 2, c is the width of the column, and b is the radius of toroidal shell element in the proposed kinematically admissible velocity field.
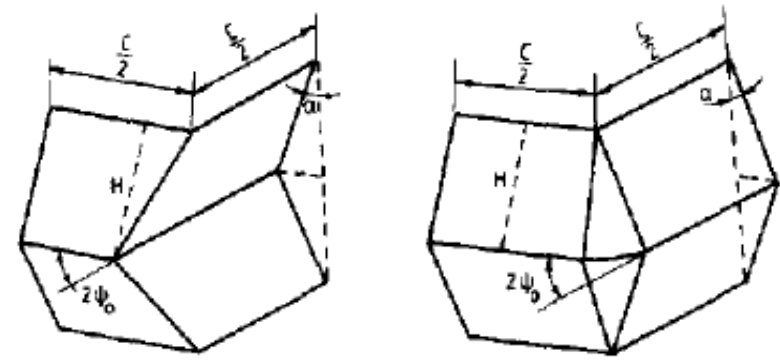

(a) (b)

Figure 3: Superfolding-elements: (a) type I (b) type II [58].

Idealized collapse behavior of square tubes can be predicted through the combinations of these two basic types of superfolding-elements. The mean collapse load for the column can then be determined by first equating the internal energy given as a summation of $E_{1} S$ and $E_{2} S$ to the external work, and then minimizing the expression with respect to $\mathrm{b}$ and $\mathrm{H}$. Table 1 lists four idealized modes of collapse and theoretically predicted mean collapse loads and half-fold lengths for a square column that failed in one of these collapse modes.

\begin{tabular}{|c|c|c|c|}
\hline $\begin{array}{c}\text { Collapse } \\
\text { mode }\end{array}$ & SE combination & \multicolumn{2}{|c|}{$\begin{array}{l}\text { Predicted mean collapse load (P) and half-fold length } \\
(\mathrm{H})\end{array}$} \\
\hline Symmetric & $\begin{array}{l}4 \text { type } \mathrm{I} \\
\text { (1 layer) }\end{array}$ & $\begin{array}{l}\mathrm{F}_{\text {mean }}=\mathrm{M}_{0}\left(52.22(\mathrm{c} / \mathrm{h})^{1 / 3}\right) \\
\mathrm{H}=0.99 \mathrm{c}^{2 / 3} h^{1 / 3}\end{array}$ & $\begin{array}{l}(7 a) \\
(7 b)\end{array}$ \\
\hline $\begin{array}{l}\text { Asymmetric } \\
\text { Mixed A }\end{array}$ & $\begin{array}{l}6 \text { type } 1+2 \text { type } \mathrm{II} \\
\text { (2 layers) }\end{array}$ & $\begin{array}{l}\mathrm{F}_{\text {mean }}=\mathrm{M}_{0}\left(42.92(\mathrm{c} / \mathrm{h})^{1 / 3}+3.17(\mathrm{c} / \mathrm{h})^{2 / 3}+\right. \\
2.04) \\
\mathrm{H}=0.78 \mathrm{c}^{2 / 3} h^{1 / 3}\end{array}$ & $\begin{array}{l}(8 a) \\
(8 b)\end{array}$ \\
\hline $\begin{array}{l}\text { Asymmetric } \\
\text { Mixed B }\end{array}$ & $\begin{array}{l}7 \text { type } \mathrm{I}+1 \text { type } \mathrm{II} \\
\text { (2 layers) }\end{array}$ & $\begin{array}{l}\mathrm{F}_{\text {mean }}=\mathrm{M}_{0}\left(45.90(\mathrm{c} / \mathrm{h})^{1 / 3}+1.75(\mathrm{c} / \mathrm{h})^{2 / 3}+\right. \\
1.02) \\
\mathrm{H}=0.86 \mathrm{c}^{2 / 3} h^{1 / 3}\end{array}$ & $\begin{array}{l}(9 a) \\
(9 b)\end{array}$ \\
\hline Extensional & $\begin{array}{l}4 \text { type } \mathrm{II} \\
\text { (1 layer) }\end{array}$ & $\begin{array}{l}\mathrm{F}_{\text {mean }}=\mathrm{M}_{0}\left(32.64(\mathrm{c} / \mathrm{h})^{1 / 3}+8.16\right) \\
\mathrm{H}=\mathrm{c}^{1 / 2} h^{1 / 2}\end{array}$ & $\begin{array}{l}(10 a) \\
(10 b)\end{array}$ \\
\hline
\end{tabular}

Table 1: Collapse modes of square columns under axial loading [59] 
The $P_{m}$ values in Table 1 are determined using the effective axial crushing distance of a column, $d_{\max }$. The values for $d_{\max }$ were theoretically predicted by idealizing the deformation at the comers as the bending of a metal sheet about two orthogonal axes [61]. With slight modifications made based on the experimental observations [17], the effective crushing distance is found to be:

$$
\frac{\mathrm{d}_{\max }}{2 \mathrm{H}}=0.73
$$

for the symmetric collapse mode, while for the other three collapse modes:

$$
\frac{\mathrm{d}_{\max }}{2 \mathrm{H}}=0.77
$$

These values are in agreement with earlier experimental results for empty columns [63]. Furthermore, if the column is stiffened from the inside, it can be proven that these values will become smaller [64]. Using equations (7a)-(10), it is shown that the extensional mode of collapse will be the controlling mode for narrow, thick, square tubes $(c / h \leq 7.5)$ while for wide, thin tubes $(c / h \geq 40.8)$, the symmetric mode will prevail. For the width-to-thickness ratio between these two values, it is likely that the imperfections in the material, whether in the form of material flows or intentionally introduced beneficial imperfections [65], will play a significant role in the onset of buckling. The strain hardening effects were taken into account in the above analysis through the use of energy equivalent flow stress, $\sigma_{0}$, as defined in [66] . This expression has to be corrected when materials other than mild steel are analyzed.

The aluminium spaceframe concept has become a very attractive option in the mid ' $90 \mathrm{~s}$ as a result of the need to better address environmental issues. In order to be able to absorb the same amount of energy, aluminium components used in structures need to be thicker than their steel counterparts due to their lower yield and ultimate strength. Combined with their generally lower ductility, this increase in thickness might lead to premature failure of material during deformation. Despite all this, weight savings of as much as $25 \%$, while keeping the adequate crashworthiness, have been reported when replacing the more conventional steel structures with aluminium. Prior to the study by Langseth and Hopperstad [3], there was limited reported experimental data for crushing aluminium. They performed extensive experimental and finite element analyses on the static and dynamic axial crushing of thin-walled aluminium extrusions $[3,12]$. In these studies, AA6060 square tubes in two different tempers of T4 and T6 with a slenderness range of $31.4 \leq c / h \leq 43.3$ were examined. In all the quasi-static cases, the progressive symmetric mode of deformation was observed. The mean collapse load was predicted within $\pm 10 \%$ using equation ( $7 \mathrm{a}$ ) and the flow stress taken as the mean value between stress at $0.2 \%$ plastic strain, $\sigma_{0.2}$, and the ultimate stress, $\sigma_{\mathrm{M}}$ :

$$
\sigma_{0}=0.5\left(\sigma_{0.2}+\sigma_{M}\right)
$$

Alternative flow stress expressions for materials showing strain hardening are:

$$
\begin{aligned}
\sigma_{0} & =\sqrt{\frac{\sigma_{\mathrm{y}} \sigma_{\mathrm{u}}}{\mathrm{n}+1}} \\
\sigma_{0} & =2.23^{\mathrm{n}} \frac{\sigma_{\mathrm{u}}}{\mathrm{n}+1}\left[\frac{2}{\mathrm{n}+2}\right]^{2 / 3}\left[\frac{\mathrm{h}}{\mathrm{c}}\right]^{(4 . \mathrm{n}) / 9}
\end{aligned}
$$

as suggested by Santosa et al. [67] and Hanssenet al. [68], respectively. In the above equations, $\mathrm{n}$ represents the strain hardening exponent of the column-wall material.

\subsection{Bending Collapse of Columns}

The bending collapse of thin-walled columns is usually localized at plastic hinges while the other sections of the column behave as rotating rigid bodies. The resistance to collapse drops significantly after this localized collapse at relatively small displacements, as can be seen from 
Figure 4. This will result in a low energy absorption efficiency of columns in pure bending. A first comprehensive study of deep bending collapse of prismatic columns was made by Kecman (1983). From extensive experimental study on rectangular columns with 27 different sections, he observed four distinct phases in the hinge development: (i) forming of a "bulge" in the web without apparent rolling deformation $\left(\mathrm{A}_{1}\right.$ in Figure $\left.4 \mathrm{~d}\right)$, (ii) rolling deformation $\left(\mathrm{A}_{2}\right.$ in Figure $4 d$ ), (iii) "jamming" of the rolling deformations and creation of new bending lines $\left(\mathrm{A}_{3}\right.$ in Figure 4d), (iv) two buckled halves coming in contact followed by the total jamming of the original hinge and the initiation of an adjacent secondary hinge. The theoretical analysis that he developed was based on the second phase in the hinge development. The nominal value of energy absorbed at a hinge consists of eight different energies generated through the bending along lines or groups of lines (Figure $4 \mathrm{c}$ ) and is given as:

$$
\mathrm{E}(\theta)=\sum_{1}^{8} \mathrm{E}_{\mathrm{i}}(\theta)
$$

where $\mathrm{E}$ is the absorbed energy and $\theta$ is the hinge rotation angle. The theoretical approach suggested by Kecman is semi-empirical since the so-called "rolling radius" has to be experimentally determined. A similar approach based on the kinematics method of plasticity that involves determining the proper folding mechanism with stationary and moving hinges was developed independently by [69]. However, Kecman's study [70] showed very good agreement between theoretical predictions and experimental results for the wide range of sections, while no experimental validation was given for Abramowicz's approach.

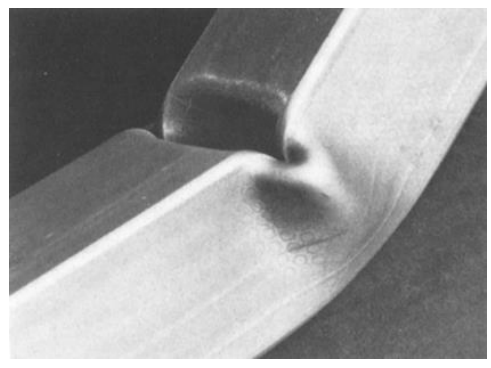

(a)

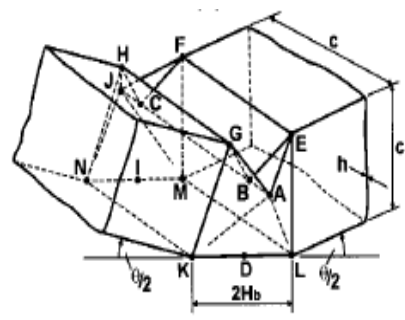

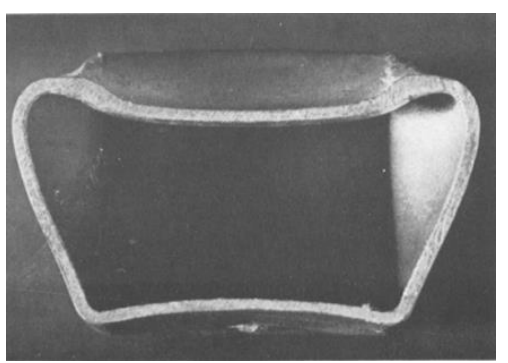

(b)

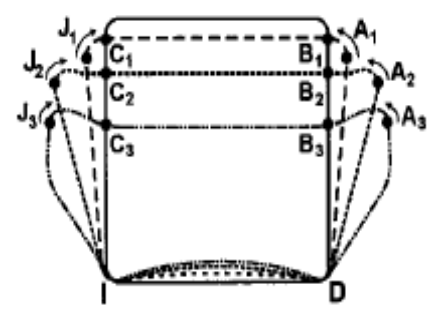

(d)

Figure 4: Analysis of bending collapse of columns by Kecman: (a) typical hinge collapse mechanism (b) cross section at the hinge (c) theoretical model (d) development stages of hinge [70]

The above methods were further extended by Wierzbicki et al. [71] (Figure 5). They first generated numerical solutions for square prismatic columns with three different width-tothickness ratios using high accuracy FE models (very dense mesh) in ABAQUS. They also extended the concept of superfolding-element to develop a superbeam element. The simplified geometry of this element is shown in Figure 5b. The closed-form solution for the momentrotation characteristic was derived by considering the superbeam element subjected to an eccentric force acting at the center of the compression flange. Furthermore, they showed that bending performance indicators could in this case be derived from the performance indicators of 
identical columns subjected to axial crushing. The half-length of the fold in bending was observed to be higher than that in the axial compression and was expressed as:

$$
\mathrm{H}_{\mathrm{b}}=1.276 \mathrm{c}^{2 / 3} \mathrm{~h}^{1 / 3}
$$

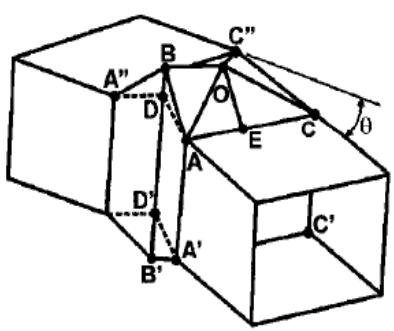

(a)

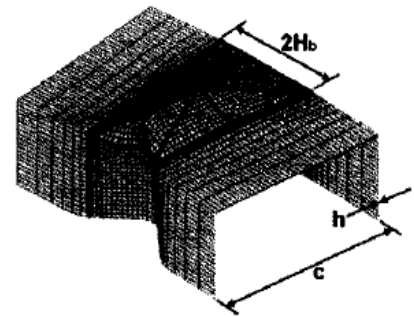

(b)

Figure 5: Analysis of bending collapse of columns by Wierzbicki: (a) simplified collapse mode of a column in bending and (b) the collapse mode superposed on the deformed FE mode [71].

Kim and Wierzbicki have used a similar approach of first generating a large set of numerical results in order to describe the behavior of square and rectangular beams subjected to more complex biaxial bending [72] and simultaneous compression and bending [73], The authors concluded that general moment-rotation characteristics that were observed in planar bending can also be observed in biaxial bending. However, the behavior observed for combined compression and bending differed somewhat from the typical bending response in that after the peak point was reached, the load decayed dramatically.

\subsection{Modes of Collapse under Combined Loading}

An energy absorbing structure will seldom be subjected to only pure axial or pure bending collapse during an actual crush event. Rather, both axial loading and moment will be generated in the structure causing oblique loading conditions. It is important to understand what happens to the structure during oblique impact since the bending collapse of components does not match crashworthiness design targets due to the low energy absorbing capacity. Limited studies in this area have been carried out until now.

Kim \& Wierzbicki [73] identified two types of oblique crushing: off-axis crushing and angled crushing (Figure 6). They found that tested E-glass/polyester pultruded tubes generally absorbed more energy in the angled loading, which they argued was due to the existence of static friction in the angled crushing in contrast to the dynamic friction in the off-axis crushing. In addition, the difference in energy absorption was observed to be greatly dependent upon the angle of impact.

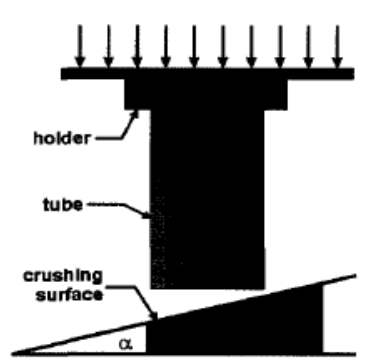

(a)

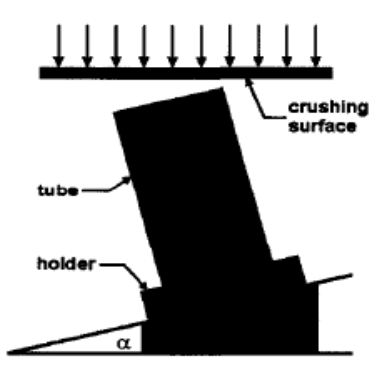

(b)

Figure 6: Types of oblique crushing: (a) angled loading, (b) off-axis loading [72] 
Han \& Park [41] used the angled loading type (Figure 6a) in their numerical analysis of oblique loading of mild steel square columns. The columns were impacted on an inclined wall at a speed of $30 \mathrm{mph}$ assuming frictionless condition. Their results showed that there exists an angle, termed critical angle, at which the transition takes place from axial to bending collapse mode. They used normalized numerical results from multiple cases to derive the approximate expressions for mean collapse load and critical load angle for the steel tubes modeled. Oblique crushing through off-axis loading (Figure 6b) was used by Reyes et al. [42] in their experimental and numerical study on aluminium extrusions. All the tested columns experienced global bending collapse with a mode of deformation at the hinge that depended on both load angle and thickness. The fractional analysis they conducted showed that the thickness was the dominant parameter, though temper and length also had considerable effects. This importance of thickness differs somewhat from the conclusions made by Han \& Park [41], primarily due to the selection of geometry and impact conditions.

Crutzen et al. [74] indicated a possible solution to the unwanted bending failure during oblique impact. They observed that the specimen could accommodate the oblique impact, i.e. fail in the more desirable progressive buckling rather than bending, if the mass and stiffness were redistributed along the specimen length. They numerically observed the improvements in the collapse mode if the variable thickness columns or the variable cross-section columns are used instead of straight columns. Earlier, Reid \& Reddy [22] did an experimental and analytical study on the tapered mild steel sheet metal tubes loaded axially and obliquely. They concluded that these tubes withstand oblique impact loads as effectively as axial loads, and that such tubes are preferable to straight tubes since they are less likely to fail by global buckling in off-axis impact.

\section{CONCLUSION}

This paper summarized the relevant theoretical and experimental work existing in the literature in the field of structural collapse. The review addressed the following four areas, which are: vehicle crashworthiness, the collapse mode of structural components, the characteristics of aluminium foams, and the use of aluminium foams as fillers in structural components.

\section{REFERENCES}

[1] Motavalli, J. For Lightweight Cars, a Materials Race. Retrieved October 11, 2012, from http://www.nytimes.com/2012/10/12/automobiles/for-lightweight-cars-a-race-among-steelaluminum-and-carbon-fiber.html?_r=0

[2] Lu, G. (Guoxing), \& Yu, T. X. (Tongxi). Energy absorption of structures and materials. 2003. CRC Press.

[3] Langseth, M., Hopperstad, O. S., \& Berstad, T. Crashworthiness of aluminium extrusions: validation of numerical simulation, effect of mass ratio and impact velocity. Inter. J. Impact Eng. 22(9-10), 829-854, 1999.

[4] Witteman, W. Improved vehicle crashworthiness design by control of the energy absorption for different collision situations, Dissertation of Eindhoven University of Technology, 1998.

[5] Carruthers, J. J., Kettle, A. P., \& Robinson, A. M. Energy Absorption Capability and Crashworthiness of Composite Material Structures: A Review. Appl. Mech. Rev. 51(10), 635-649, 1989.

[6] Jacob, G. C., Fellers, J. F., Simunovic, S., \& Starbuck, J. M. Energy Absorption in Polymer Composites for Automotive Crashworthiness. J. Composite Mat., 36(7), 813-850, 2002.

[7] Wallentowitz, H., \& Adam, H. Predicting the crashworthiness of vehicle structures made by lightweight design materials and innovative joining methods. Inter. J. Crashworthiness, 163-180, 1996. 
[8] Pletschen, B., Herrmann, R., Kallina, I., \& Zeidler, F. The significance of frontal offset collisions in real world accidents 900411, 1990, doi: 10.4271/900411.

[9] U.S. Department of Transportation - NHTSA. Fatalities in Frontal Crashes Despite Seat Belts and Air Bags. Retrieved February 27, 2017, from https://one.nhtsa.gov/DOT/NHTSA/NVS/Crashworthiness/Small Overlap and Oblique Research/811102.PDF

[10] Summers, S. M., Prasad, A., \& Hollowell, W. T. NHTSA's Research Program for Vehicle Aggressivity and Fleet Compatibility. Retrieved February 28, 2017, from https://www-nrd.nhtsa.dot.gov/pdf/esv/esv17/Proceed/00179.pdf

[11] Stucki, S. L., Hollowell, W. T., \& Fessahaie, O. Determination of frontal offset test conditions based on crash data. National Highway Traffic Safety Administration, 1998.

[12] Langseth, M., \& Hopperstad, O. S. Static and dynamic axial crushing of square thinwalled aluminium extrusions. Inter. J. Impact Eng. 18(7-8), 949-968, 1996.

[13] Jensen, Ø., Langseth, M., \& Hopperstad, O. S. Experimental investigations on the behaviour of short to long square aluminium tubes subjected to axial loading. International Journal of Impact Engineering, 30(8-9), 973-1003, 2004.

[14] Zhang, X., \& Cheng, G. A comparative study of energy absorption characteristics of foam-filled and multi-cell square columns. Inter. J. Impact Eng. 34(11), 1739-1752, 2007.

[15] Alghamdi, A. A. Collapsible impact energy absorbers: An overview. Thin-Walled Struct. 39(2), 189-213, 2001.

[16] Alexander, J. M. An Approximate Analysis of the Collapse of Thin Cylindrical Shells under Axial Loading. The Quarterly J. Mech. Appl. Math., 13(1), 10-15, 1960.

[17] Abramowicz, W., \& Jones, N.. Dynamic axial crushing of square tubes. Inter. J. Impact Eng. 2(2), 179-208, 1984.

[18] Abramowicz, W., \& Jones, N. Dynamic progressive buckling of circular and square tubes. Inter. J. Impact Eng. 4(4), 243-270, 1986.

[19] Guillow, S. R., Lu, G., \& Grzebieta, R. H. Quasi-static axial compression of thin-walled circular aluminium tubes. Inter. J. Mech. Sci. 43(9), 2103-2123, 2001.

[20] Al Galib, D., \& Limam, A. Experimental and numerical investigation of static and dynamic axial crushing of circular aluminum tubes. Thin-Walled Structures, 42(8), $1103-$ 1137, 2004.

[21] Salehghaffari, S., Tajdari, M., Panahi, M., \& Mokhtarnezhad, F. Attempts to improve energy absorption characteristics of circular metal tubes subjected to axial loading. ThinWalled Structures, 48(6), 379-390, 2010.

[22] Reid, S. R., \& Reddy, T. Y. Static and dynamic crushing of tapered sheet metal tubes of rectangular cross-section. Inter. J. Mech. Sci. 28(9), 623-637, 1986.

[23] Singace, A. ., El-Sobky, H., \& Petsios, M. Influence of end constraints on the collapse of axially impacted frusta. Thin-Walled Structures, 39(5), 415-428, 2001.

[24] Ahmad, Z., Thambiratnam, D. P., \& Tan, A. C. C. Dynamic energy absorption characteristics of foam-filled conical tubes under oblique impact loading. Inter. J. Impact Eng. 37(5), 475-488, 2010.

[25] Nagel, G. M., \& Thambiratnam, D. P. A numerical study on the impact response and energy absorption of tapered thin-walled tubes. Inter. J. Mech. Sci. 46(2), 201-216, 2004.

[26] Mirfendereski, L., Salimi, M., \& Ziaei-Rad, S. Parametric study and numerical analysis of empty and foam-filled thin-walled tubes under static and dynamic loadings. Inter. J. Mech. Sci. 50(6), 1042-1057, 2008.

[27] Chen, W., \& Wierzbicki, T. Relative merits of single-cell, multi-cell and foam-filled thinwalled structures in energy absorption. Thin-Walled Structures, 39(4), 287-306, 2001.

[28] Kim, H.-S. New extruded multi-cell aluminum profile for maximum crash energy absorption and weight efficiency. Thin-Walled Structures, 40(4), 311-327, 2002.

[29] Zhang, X., Cheng, G., You, Z., \& Zhang, H. Energy absorption of axially compressed thin-walled square tubes with patterns. Thin-Walled Structures, 45(9), 737-746, 2007. 
[30] Aktay, L., Kröplin, B.-H., Toksoy, A. K., \& Güden, M. Finite element and coupled finite element/smooth particle hydrodynamics modeling of the quasi-static crushing of empty and foam-filled single, bitubular and constraint hexagonal- and square-packed aluminum tubes. Materials \& Design, 29(5), 952-962, 2008.

[31] Liu, Y. Crashworthiness design of multi-corner thin-walled columns. Thin-Walled Structures, 46(12), 1329-1337, 2008.

[32] Daneshi, G. ., \& Hosseinipour, S. Grooves effect on crashworthiness characteristics of thin-walled tubes under axial compression. Materials \& Design, 23(7), 611-617, 2002.

[33] Avalle, M., Belingardi, G., \& Montanini, R. Characterization of polymeric structural foams under compressive impact loading by means of energy-absorption diagram. Inter. J. Impact Eng. 25(5), 455-472, 2001.

[34] Gameiro, C. P., \& Cirne, J. Dynamic axial crushing of short to long circular aluminium tubes with agglomerate cork filler. Inter. J. Mech. Sci. 49(9), 1029-1037, 2007.

[35] Seitzberger, M., Rammerstorfer, F. G., Gradinger, R., Degischer, H. P., Blaimschein, M., $\&$ Walch, C. Experimental studies on the quasi-static axial crushing of steel columns filled with aluminium foam. Inter. J. Solids Struct. 37(30), 4125-4147, 2000.

[36] Mantena, P. R., \& Mann, R. Impact and dynamic response of high-density structural foams used as filler inside circular steel tube. Compos. Struct. 61(4), 291-302, 2003.

[37] Zarei, H. R., \& Kröger, M. Bending behavior of empty and foam-filled beams: Structural optimization. Inter. J. Impact Eng. 35(6), 521-529, 2008.

[38] Mohamed Sheriff, N., Gupta, N. K., Velmurugan, R., \& Shanmugapriyan, N. Optimization of thin conical frusta for impact energy absorption. Thin-Walled Structures, 46(6), 653-666, 2008.

[39] Shariatpanahi, M., Masoumi, A., \& Ataei, A. Optimum design of partially tapered rectangular thin-walled tubes in axial crushing. Proceedings of the Institution of Mechanical Engineers, Part B: Journal of Engineering Manufacture, 222(2), 285-291, 2008.

[40] Hou, S., Li, Q., Long, S., Yang, X., \& Li, W. Multiobjective optimization of multi-cell sections for the crashworthiness design. Inter. J. Impact Eng.35(11), 1355-1367, 2008.

[41] Han, D. C., \& Park, S. H. Collapse behavior of square thin-walled columns subjected to oblique loads. Thin-Walled Structures, 35(3), 167-184, 1999.

[42] Reyes, A., Langseth, M., \& Hopperstad, O. S. Crashworthiness of aluminum extrusions subjected to oblique loading: experiments and numerical analyses. Inter. J. Mech. Sci. 44(9), 1965-1984, 2002.

[43] Reyes, A., Langseth, M., \& Hopperstad, O. S. Square aluminum tubes subjected to oblique loading. Inter. J. Impact Eng. 28(10), 1077-1106, 2003.

[44] Reyes, A., Hopperstad, O. S., \& Langseth, M. Aluminum foam-filled extrusions subjected to oblique loading: experimental and numerical study. Inter. J. Solids Struct. 41(5-6), 1645-1675, 2004.

[45] Nagel, G. M., \& Thambiratnam, D. P. Dynamic simulation and energy absorption of tapered thin-walled tubes under oblique impact loading. Inter. J. Impact Eng. 32(10), 1595-1620, 2006.

[46] Ismail, A. Energy absorption of foam-filled steel extrusion under quasi-static oblique loading. Inter. J. Eng. Tech. 5(1), 11-24, 2008.

[47] Qi, C., Yang, S., \& Dong, F. Crushing analysis and multiobjective crashworthiness optimization of tapered square tubes under oblique impact loading. Thin-Walled Structures, 59, 103-119, 2012.

[48] Song, J. Numerical simulation on windowed tubes subjected to oblique impact loading and a new method for the design of obliquely loaded tubes. International Journal of Impact Engineering, 54, 192-205, 2013.

[49] Fang, J., Gao, Y., Sun, G., Qiu, N., \& Li, Q. On design of multi-cell tubes under axial and oblique impact loads. Thin-Walled Structures, 95, 115-126, 2015.

[50] Zhang, Y., Sun, G., Xu, X., Li, G., \& Li, Q. Multiobjective crashworthiness optimization 
of hollow and conical tubes for multiple load cases. Thin-Walled Structures, 82, 331-342, 2014.

[51] Yang, S., \& Qi, C. Multiobjective optimization for empty and foam-filled square columns under oblique impact loading. Inter. J. Impact Eng. 54, 177-191, 2013.

[52] Djamaluddin, F., Abdullah, S., Ariffin, A. K., \& Nopiah, Z. M. Optimization of foamfilled double circular tubes under axial and oblique impact loading conditions. ThinWalled Structures, 87, 1-11, 2015.

[53] Hou, S., Han, X., Sun, G., Long, S., Li, W., Yang, X., \& Li, Q. Multiobjective optimization for tapered circular tubes. Thin-Walled Structures, 49(7), 855-863, 2011.

[54] Hou, S., Li, Q., Long, S., Yang, X., \& Li, W. Design optimization of regular hexagonal thin-walled columns with crashworthiness criteria. Finite Elements in Analysis and Design, 43(6-7), 555-565, 2007

[55] Tarlochan, F. Design, fabrication and evaluation of composite sandwich panels for crashworthiness. Universiti Putra Malaysia, Malaysia, 2007.

[56] Johnson, W., \& Soden, P. Inextensional collapse of thin-walled tubes under axial compression. J. Strain, 12(4), 317-330, 1977.

[57] Mamalis, A., Manolakos, D., \& Demosthenous, G. The static and dynamic axial crumbling of thin-walled fibreglass composite square tubes. Composites Part B: Engineering, 28(4), 439-451, 1993.

[58] Thornton, P. H., \& Jeryan, R. A. Crash energy management in composite automotive structures. International Journal of Impact Engineering, 7(2), 167-180, 1998.

[59] Wierzbicki, T., \& Bhat, S. A moving hinge solution for axisymmetric crushing of tubes. Inter. J. Mech. Sci. 28(3), 135-151, 1986.

[60] Wierzbicki, T., Bhat, S., \& Abramowicz, W. Alexander revisited-a two folding elements model of progressive crushing of tubes. Inter. J. Solids Struc. 29(24), 32693288, 1992.

[61] Wierzbicki, T., \& Abramowicz, W. On the Crushing Mechanics of Thin-Walled Structures. J. Appl. Mech. 50(4a), 727-734, 1983.

[62] Hayduk, R. J., \& Wierzbicki, T. Extensional collapse modes of structural members. Computers \& Structures, 18(3), 447-458, 1984.

[63] Ohkubo, Y., Akamatsu, T., \& Shirasawa, K. Mean Crushing Strength of Closed-Hat Section Members (p. 740040). Detroit: SAE Technical Paper, 1974. http://doi.org/10.4271/740040

[64] Abramowicz, W. The effective crushing distance in axially compressed thin-walled metal columns. Inter. J. Impact Eng. 1(3), 309-317, 1983.

[65] Hui, D. Design of beneficial geometric imperfections for elastic collapse of thin-walled box columns. Inter. J. Mech. Sci. 28(3), 163-172, 1986.

[66] Wierzbicki, T., \& Abramowicz, W. The Mechanics of Deep Plastic Collapse of Thinwalled S tructures. Structural Failure, 1989, New York: Wiley.

[67] Santosa, S. P., Wierzbicki, T., Hanssen, A. G., \& Langseth, M. Experimental and numerical studies of foam-filled sections. Inter. J. Impact Eng. 24(5), 509-534, 2000.

[68] Hanssen, A. G., Langseth, M., \& Hopperstad, O. S. Static and dynamic crushing of square aluminium extrusions with aluminium foam filler. Inter. J. Impact Eng. 24(4), 347-383, 2000.

[69] Abramowicz, W. Simplified Crushing Analysis of Thin-Walled Columns and Beams. Eng. Trans., 29, 3-27, 1981.

[70] Kecman, D. Bending collapse of rectangular and square section tubes. Inter. J. Mech. Sci. 25(9-10), 623-636, 1983.

[71] Wierzbicki, T., Recke, L., Abramowicz, W., Gholami, T., \& Huang, J. Stress profiles in thin-walled prismatic columns subjected to crush loading-II. Bending. Computers \& Structures, 51(6), 625-641, 1994.

[72] Kim, H.-S., \& Wierzbicki, T. Numerical and analytical study on deep biaxial bending collapse of thin-walled beams. Inter. J. Mech. Sci. 42(10), 1947-1970, 2000. 
[73] Kim, H.-S., \& Wierzbicki, T. Crush behavior of thin-walled prismatic columns under combined bending and compression. Computers \& Structures, 79(15), 1417-1432, 2001.

[74] Crutzen, Y., Inzaghi, A., Mogilevsky, M., \& Albertini, C. Computer Modelling of the Energy Absorption Process in Box-type Structures under Oblique Impact. Automotive Automation Limited (UK, 1293-1298, 1996 